\title{
Predicting Genotype and Survival in Glioma Using Standard Clinical MR Imaging Apparent Diffusion Coefficient Images: A Pilot Study from The Cancer Genome Atlas
}

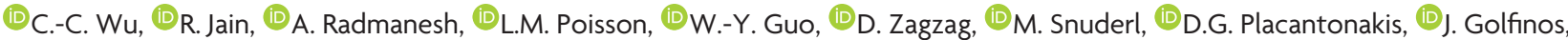 \\ and (iD)A.S. Chi
}

\begin{abstract}
BACKGROUND AND PURPOSE: Few studies have shown MR imaging features and ADC correlating with molecular markers and survival in patients with glioma. Our purpose was to correlate MR imaging features and ADC with molecular subtyping and survival in adult diffuse gliomas.
\end{abstract}

MATERIALS AND METHODS: Presurgical MRIs and ADC maps of 131 patients with diffuse gliomas and available molecular and survival data from The Cancer Genome Atlas were reviewed. MR imaging features, ADC (obtained by ROls within the lowest ADC area), and mean relative $A D C$ values were evaluated to predict isocitrate dehydrogenase (IDH) mutation, $1 \mathrm{p} / 19 \mathrm{q}$ codeletion status, MGMT promoter methylation, and overall survival.

RESULTS: IDH wild-type gliomas tended to exhibit enhancement, necrosis, and edema; $>50 \%$ enhancing area $(P<.001)$; absence of a cystic area $(P=.013)$; and lower mean relative ADC (median, 1.1 versus 1.6; $P<.001$ ) than IDH-mutant gliomas. By means of a cutoff value of 1.08 for mean relative $A D C$, IDH-mutant and IDH wild-type gliomas with lower mean relative $A D C(<1.08)$ had poorer survival than those with higher mean relative ADC (median survival time, 24.2 months; $95 \% \mathrm{Cl}, 0.0-54.9$ months versus 62.0 months; $P=.003$; and median survival time, 10.4 months; $95 \% \mathrm{Cl}, 4.4-16.4$ months versus 17.7 months; $95 \% \mathrm{Cl}, 11.6-23.7$ months; $P=.041$, respectively), regardless of World Health Organization grade. Median survival of those with IDH-mutant glioma with low mean relative ADC was not significantly different from that in those with IDH wild-type glioma. Other MR imaging features were not statistically significant predictors of survival.

CONCLUSIONS: IDH wild-type glioma showed lower ADC values, which also correlated with poor survival in both IDH-mutant and IDH wild-type gliomas, irrespective of histologic grade. A subgroup with IDH-mutant gliomas with lower ADC had dismal survival similar to that of those with IDH wild-type gliomas.

ABBREVIATIONS: $I D H=$ isocitrate dehydrogenase $; \max =$ maximum; $m i n=$ minimum; $r A D C=$ relative $A D C ; r A D C$ mean $=$ mean relative $A D C ; T C G A=$ The $C a n c e r$ Genome Atlas; WHO = World Health Organization

G liomas are a heterogeneous group of tumors, and the clinical aggressiveness and prognoses are diverse among different histopathologic grades and molecular subtypes. Previous studies have shown that histopathologic classification of diffuse gliomas

Received April 25, 2018; accepted after revision July 2.

From the Department of Radiology (C.-C.W., W.-Y.G.), Taipei Veterans General Hospital, Taipei, Taiwan, Republic of China; School of Medicine (C.-C.W., W.-Y.G.), National Yang-Ming University, Taipei, Taiwan, Republic of China; Departments of Radiology (C.-C.W., R.J., A.R.), Neurosurgery (R.J., D.P., J.G.), and Pathology (D.Z., M.S.), NYU School of Medicine, New York, New York; Department of Public Health Sciences and Hermelin Brain Tumor Center (L.M.P.), Henry Ford Hospital, Detroit, Michigan; and Neuro-Oncology Program (A.S.C.), Laura and Isaac Perlmutter Cancer Center, NYU School of Medicine and Langone Health, New York, New York.

Chih-Chin Wu and Rajan Jain contributed equally to the article.

Please address correspondence to Rajan Jain, MD, Department of Radiology, NYU School of Medicine, 660 First Ave, 2nd Floor, New York, NY 10016; e-mail:

rajan.jain@nyumc.org

http://dx.doi.org/10.3174/ajnr.A5794 has high interobserver variation and correlates imperfectly with clinical outcomes. ${ }^{1,2}$ Nevertheless, molecular markers, particularly isocitrate dehydrogenase (IDH) mutational status, have been demonstrated to be significant and more robust prognostic mark$\mathrm{ers}^{3}$ and have been incorporated into the classification of diffuse gliomas in the latest update of the World Health Organization (WHO) classification in 2016. ${ }^{4}$ IDH mutation, a powerful prognostic marker of improved survival in diffuse glioma, is found mainly in lower grade gliomas (WHO grades II and III), but also in glioblastoma (WHO grade IV), though at much lower frequency. ${ }^{5,6}$

Preoperative and noninvasive determination of molecular subtyping is of great value in the clinical management of patients with glioma. However, studies correlating MR imaging features with $I D H$-mutation status and patient survival in diffuse gliomas are scarce. Recently, we showed that the "T2-FLAIR mismatch sign," detectable using conventional MR imaging, is a highly spe- 
cific imaging biomarker for the $I D H$-mutant, $1 \mathrm{p} / 19 \mathrm{q}$ noncodeleted molecular subtype in lower grade gliomas. ${ }^{7}$ Wang et $\mathrm{al}^{8}$ demonstrated that the absence of contrast enhancement was associated with longer progression-free and overall survival in patients with IDH1-mutated anaplastic gliomas. MR spectroscopy could detect 2-hydroxyglutarate, a metabolite that accumulates in $\mathrm{IDH}$-mutant gliomas but did not discover a survival difference. ${ }^{9}$ Blood volume estimates obtained by MR perfusion have also provided potential markers for noninvasive assessment of $I D H$ status. ${ }^{10}$

ADC can be calculated from DWI, and tumors with more freely mobile water molecules and lesser cellularity have higher ADC values. ${ }^{11}$ ADC has been shown to be a valuable imaging marker in the diagnosis of intracranial lesions as well as in grading brain tumors. ${ }^{11-15}$ Therefore, we hypothesized that ADC values obtained from conventional MR imaging could correlate with molecular subtype and patient survival in adult diffuse gliomas.

\section{MATERIALS AND METHODS}

This was a retrospective study using data from the publicly available National Institutes of Health/National Cancer Instituteapproved databases of The Cancer Genome Atlas (TCGA; https://cancergenome.nih.gov) and The Cancer Imaging Archive (http://www.cancerimagingarchive.net/), ${ }^{16-18}$ from which all 461 cases with imaging data were reviewed, and only cases of treatmentnaïve diffuse gliomas (WHO grades II-IV) with available DWI and ADC maps were included. WHO grade, the status of 3 validated molecular prognostic markers (IDH mutation, 1p/19q codeletion, MGMT promoter methylation), and survival data were retrieved from The Cancer Genome Atlas. MR images were reviewed, in consensus, by 2 board-certified neuroradiologists (with 8 and 17 years of experience) who were blinded to pathologic and molecular diagnosis. The order of cases viewed was randomized to avoid bias.

Each tumor was scored for $9 \mathrm{MR}$ imaging features according to the following criteria modified from the Visually Accessible Rembrandt Images MR imaging feature set ${ }^{19}$ : T2 signal intensities (higher than gray matter or mixed [the presence equal to or darker than that of gray matter part]); T2 homogeneity (homogeneous or heterogeneous); margin (well-defined or not well-defined [either infiltrative or irregular]); edema (none to minimal or mild to marked); enhancing pattern (non-/minimally enhancing or enhancing); portion of enhancing area $(<50 \%$ or $\geq 50 \%)$; the presence of cystic areas (presence or absence); and the presence of necrotic areas (presence or absence). We investigated the relationship among 9 different MR imaging features and 3 molecular markers (IDH mutation, $1 \mathrm{p} / 19 \mathrm{q}$ codeletion, and MGMT promoter methylation) as well as WHO grade and overall survival.

Diffusion-weighted images were analyzed using OsiriX Imaging Software (http://www.osirix-viewer.com). ADC measurements were generated by manually drawing 3 nonoverlapping ROIs ranging from 40 to $60 \mathrm{~mm}^{2}$ within the region of lowest ADC values within the solid component of each tumor on ADC maps. The ADC value was also calculated from contralateral normalappearing white matter by drawing a single ROI with a size similar to that of a tumoral ROI. We obtained mean, minimum (min), and maximum ( $\max )$ ADCs of each tumor, respectively, by averaging the 3 ROIs; and relative $\mathrm{ADC}\left(\mathrm{rADC}_{\text {mean }}, \mathrm{rADC}_{\text {min }}\right.$, and
$\mathrm{rADC}_{\max }$ ) was calculated by dividing the tumor ADC by the ADC of the contralateral normal-appearing white matter.

\section{Statistical Analysis}

The Kolmogorov-Smirnov test was used to determine whether the numeric data (age and relative ADC values) for each group were normally distributed. Independent variables (clinical parameter and MR imaging features) were compared using the $\chi^{2}$ test among different molecular groups. Normally distributed continuous variables (eg, age) were compared using the independent $t$ test or ANOVA test, and non-normally distributed continuous variables $\left(\mathrm{rADC}_{\text {mean }}, \mathrm{rADC}_{\text {min }}\right.$, and $\mathrm{rADC}_{\text {max }}$ ) were compared using the Mann-Whitney $U$ test among different molecular groups. The intraobserver reliability of ADC value measuring was tested using intraclass correlation coefficients. The optimal cutoff value of each $\mathrm{rADC}$ was obtained from receiver operating characteristic curve analysis when the Youden index reached a maximum. Survival curves were estimated and plotted by the KaplanMeier method with log-rank tests to compare Kaplan-Meier curves among groups. Variables were first analyzed by the univariate model. MR imaging features and clinical and molecular parameters (including age, sex, WHO grade, MGMT promoter methylation status, $I D H$ mutation status, and $1 \mathrm{p} / 19 \mathrm{q}$ codeletion status) with statistical significance in univariate analysis $(P<.05)$ were entered into a Cox proportional hazards ratio model for multivariate analysis. Statistical significance was defined as $P<.05$ for all tests. The statistical analyses were performed using the statistical software package SPSS 23.0 (IBM, Armonk, New York) and R statistical and computing software, Version 3.3.2 (http://www.r-project.org).

\section{RESULTS}

A total of 131 (59 [45\%] IDH wild-type and 72 [55\%] IDH-mutant) gliomas were included in this study. Of the $72 \mathrm{IDH}$-mutant tumors, $26(36 \%)$ were $1 \mathrm{p} / 19 \mathrm{q}$ codeleted and 46 (64\%) were non$1 \mathrm{p} / 19 \mathrm{q}$ codeleted. Patients in the $I D H$ wild-type group (mean, $60 \pm 12.2$ years) were significantly older than those in the $I D H$ mutant group (mean, $45.1 \pm 13.9$ years), and patients with $I D H$ mutant, $1 \mathrm{p} / 19 \mathrm{q}$ codeleted gliomas (mean, $50.7 \pm 13.9$ years) were older than those with $I D H$-mutant, non-1p/19q codeleted gliomas (mean, $41.9 \pm 12.9$ years $)(P=.01)$.

\section{Correlation between Conventional MR Imaging Features and Molecular Subtypes}

Among the conventional MR imaging characteristics, IDH wildtype gliomas were more likely to exhibit enhancement $(P<.001)$, $>50 \%$ enhancing area $(P<.001)$, absence of cystic area $(P=$ $.013)$, the presence of necrosis $(P<.001)$, and the presence of edema $(P<.001)$. Within the $I D H$-mutant group, there were no MR imaging characteristics to differentiate $1 \mathrm{p} / 19 \mathrm{q}$ codeletion status using the features tested (Table 1).

\section{Correlation between rADC Values and Molecular Subtypes}

Median $\mathrm{rADC}_{\text {mean }}, \mathrm{rADC}_{\text {min }}$, and $\mathrm{rADC}_{\text {max }}$ values of $I D H$ wildtype gliomas were significantly lower than those of $I D H$-mutant gliomas $(P<.001)$ (Fig 1 and Table 1$)$. Within the $I D H$-mutant 


\begin{tabular}{|c|c|c|c|c|c|c|}
\hline & $\begin{array}{l}\text { IDH Wild- } \\
\text { Type }\end{array}$ & IDH-Mutant & $P$ & $\begin{array}{c}\text { IDH-Mutant, } \\
\text { Non-1p/19q Codeleted }\end{array}$ & $\begin{array}{l}\text { IDH-Mutant, } \\
\text { Ip/19q Codeleted }\end{array}$ & $P$ \\
\hline \multicolumn{7}{|l|}{ MR imaging features (No.) (\%) } \\
\hline \multicolumn{7}{|l|}{ T2 signal intensities ${ }^{\mathrm{a}}$} \\
\hline$>$ Gray matter & $13(22.4 \%)$ & $30(43.5 \%)$ & $.012^{c}$ & $21(48.8 \%)$ & $9(34.6 \%)$ & .248 \\
\hline$>$ Mixed & 45 (77.6\%) & $39(56.5 \%)$ & & $22(51.2 \%)$ & $17(65.4 \%)$ & \\
\hline \multicolumn{7}{|l|}{$\mathrm{T} 2$ homogeneity $^{\mathrm{a}}$} \\
\hline Homogeneous & $6(10.3 \%)$ & $14(20.3 \%)$ & .125 & $10(23.3 \%)$ & $4(15.4 \%)$ & .544 \\
\hline Heterogeneous & $52(89.7 \%)$ & $55(79.7 \%)$ & & $33(76.7 \%)$ & $22(84.6 \%)$ & \\
\hline \multicolumn{7}{|l|}{ Margin } \\
\hline Well-defined & 32 (54.2\%) & $27(38.0 \%)$ & .065 & 20 (44.4\%) & $7(26.9 \%)$ & .143 \\
\hline Mixed & $27(45.8 \%)$ & $44(62.0 \%)$ & & $25(55.6 \%)$ & $19(73.1 \%)$ & \\
\hline \multicolumn{7}{|l|}{ Edema } \\
\hline No-to-minimal & $20(33.9 \%)$ & 57 (79.2\%) & $<.001^{c}$ & $38(82.6 \%)$ & 19 (73.1\%) & .339 \\
\hline Mild-to-marked & $39(66.1 \%)$ & $15(20.8 \%)$ & & $8(17.4 \%)$ & $7(26.9 \%)$ & \\
\hline \multicolumn{7}{|l|}{ Enhancing pattern ${ }^{\mathrm{b}}$} \\
\hline None/minimally enhancing & $4(7.0 \%)$ & $30(42.3 \%)$ & $<.001^{\mathrm{c}}$ & $19(41.3 \%)$ & $11(44.0 \%)$ & .826 \\
\hline Enhancing & 55 (93.2\%) & $41(56.9 \%)$ & & $27(58.7 \%)$ & $14(56.0 \%)$ & \\
\hline \multicolumn{7}{|l|}{ Proportion of enhancing area ${ }^{\mathrm{b}}$} \\
\hline$<50 \%$ & $14(23.7 \%)$ & $63(88.7 \%)$ & $<.001^{\mathrm{c}}$ & $40(87.0 \%)$ & $23(92.0 \%)$ & .704 \\
\hline$\geq 50 \%$ & 45 (76.3\%) & $8(11.3 \%)$ & & $6(13.0 \%)$ & $2(8.0 \%)$ & \\
\hline \multicolumn{7}{|l|}{ Cystic area } \\
\hline Presence & $5(8.5 \%)$ & $28(39.4 \%)$ & $.013^{c}$ & $26(56.5 \%)$ & $17(65.4 \%)$ & .461 \\
\hline Absence & $54(91.5 \%)$ & $43(59.7 \%)$ & & $20(43.5 \%)$ & $9(34.6 \%)$ & \\
\hline \multicolumn{7}{|l|}{ Necrotic area ${ }^{b}$} \\
\hline Presence & 49 (83.1\%) & $16(22.5 \%)$ & $<.001^{c}$ & $38(82.6 \%)$ & $17(68.0 \%)$ & .159 \\
\hline Absence & $10(16.9 \%)$ & $55(77.5 \%)$ & & $8(17.4 \%)$ & $8(32.0 \%)$ & \\
\hline $\mathrm{rADC}_{\text {mean }}$ (median) & 1.1 & 1.6 & $<.001^{\mathrm{c}}$ & 1.7 & 1.5 & .071 \\
\hline $\mathrm{rADC}_{\text {min }}$ (median) & 0.9 & 1.4 & $<.001^{\mathrm{c}}$ & 1.4 & 1.3 & .178 \\
\hline $\mathrm{rADC}_{\max }$ (median) & 1.3 & 1.8 & $<.001^{\mathrm{c}}$ & 1.9 & 1.7 & .106 \\
\hline
\end{tabular}

a There were 4 cases lacking T2 MR images.

${ }^{b}$ One case in the IDH-mutant group lacked postcontrast studies.

'Statistically significant $(P<.05)$.

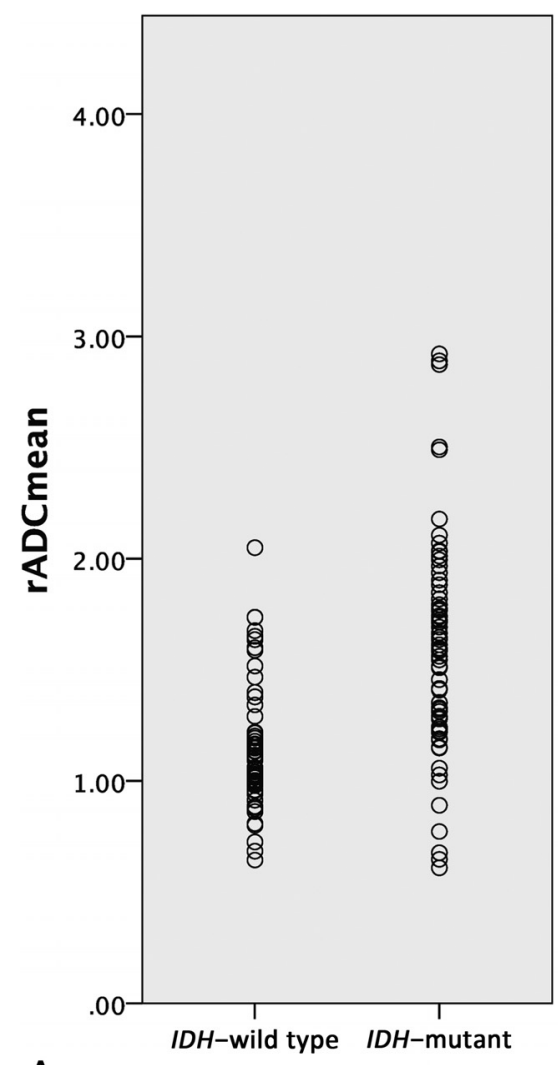

A IDH
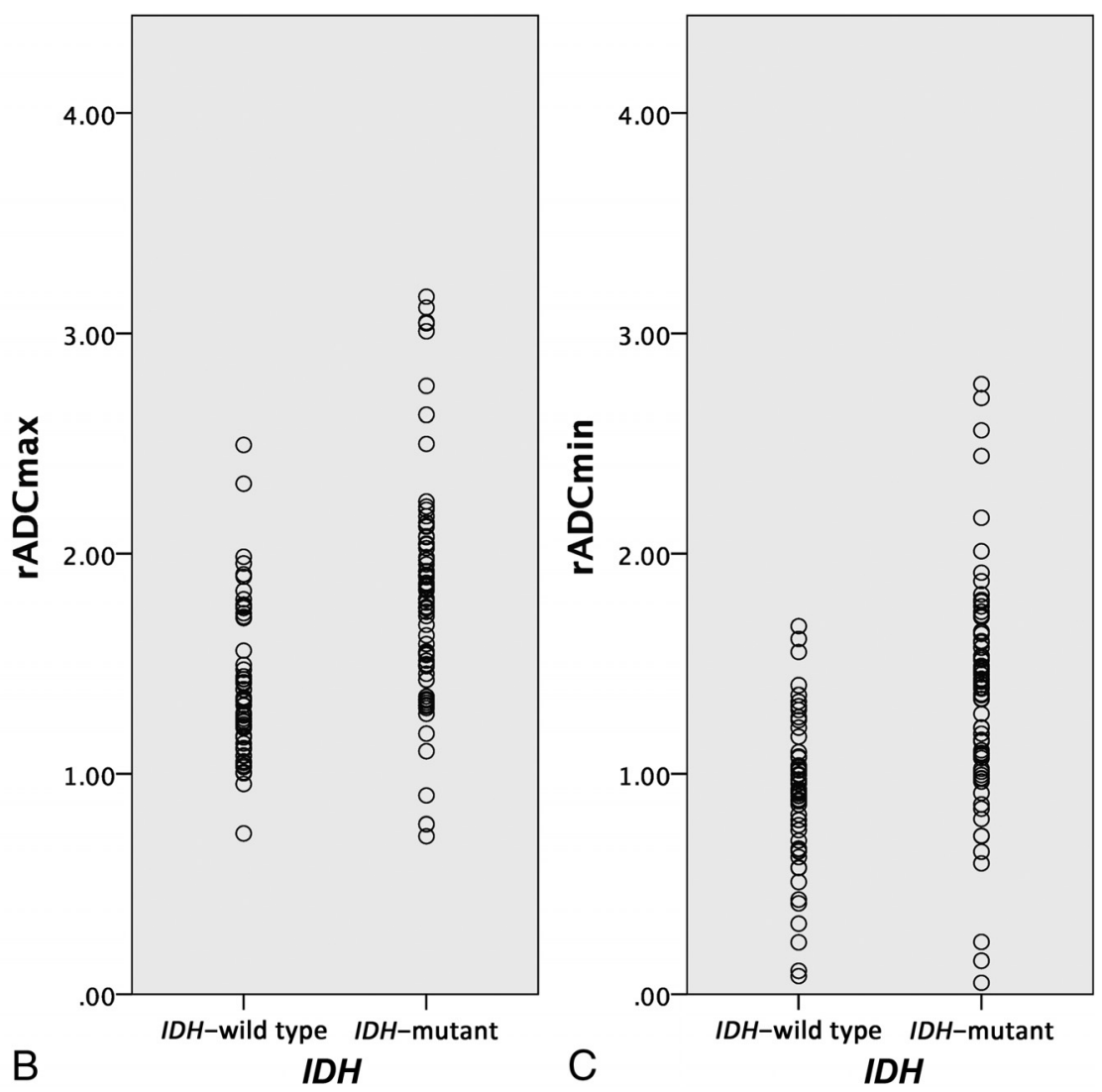

FIG 1. Boxplot representation of $\mathrm{rADC}_{\text {mean }}$ values by glioma IDH genotype. 
Table 2: Comparison of overall survival by relative ADC and glioma IDH-mutation status

\begin{tabular}{|c|c|c|c|c|}
\hline Variable $^{a}$ & Case No. & Survival Time $^{\text {b }}$ & Coefficient $(\boldsymbol{\beta})$ & $P$ Value \\
\hline IDH mutant, high $\mathrm{rADC}_{\text {mean }}$ & 63 & 62.0 & & \\
\hline vs IDH mutant, low rADC & & & .141 & .003 \\
\hline vs IDH wild-type, high $r A D C_{\text {mean }}$ & & & .06 & $<.001$ \\
\hline vs IDH wild-type, low rADC mean & & & .24 & $<.001$ \\
\hline IDH mutant, low rADC mean & 9 & $24.2(0.0-55.0)$ & & \\
\hline vs IDH wild-type, high rADC $C_{\text {mean }}$ & & & .45 & .614 \\
\hline$I D H$ wild-type, high $r A D C_{\text {mean }}$ & 30 & $17.7(11.6-23.7)$ & & \\
\hline vs IDH wild-type, low rADC & & & .25 & .041 \\
\hline$I D H$ wild-type, low $\mathrm{rADC}_{\text {mean }}$ & 29 & $10.4(4.4-16.4)$ & & \\
\hline vs IDH mutant, low rADC & & & .51 & .179 \\
\hline
\end{tabular}

glioma cohort, rADC values trended lower in $1 \mathrm{p} / 19 \mathrm{q}$ codeleted gliomas than in noncodeleted gliomas; however, this trend did not reach statistical significance. Receiver operating characteristic analysis identified an $\mathrm{rADC}_{\text {mean }}$ of 1.2 as the optimal cutoff value to differentiate $I D H$ wild-type and IDH-mutant gliomas irrespective of WHO grade, with the best combination of sensitivity $(81.9 \%)$ and specificity $(74.6 \%)$ and area under the curve $(0.790$; 95\% CI, 0.707-0.869; $P<.001)$. In the analysis of intraobserver reliability, the intraclass correlation coefficients indicated a good correlation of the first evaluator (intraclass correlation coefficient, $0.951 ; 95 \% \mathrm{CI}, 0.829-0.987 ; P<.001)$ and the second evaluator (intraclass correlation coefficient, $0.926 ; 95 \%$ CI, 0.785-0.975; $P<.001)$.

\section{Correlation between rADC and Overall Survival}

Median overall survival was 25.4 months (95\% CI, 19.0-31.7 months), and overall cumulative survival rates were $79 \%$ at 1 year, $59 \%$ at 2 years, $42 \%$ at 3 years, and $36 \%$ at 5 years in all 131 cases. Univariate survival analysis found survival to be significantly related to $6 \mathrm{MR}$ imaging features, including T2 homogeneity, enhancing pattern, enhancing areas, presence of necrosis, $\mathrm{rADC}_{\text {mean }}$, and $\mathrm{rADC}_{\text {min }}$ values, in addition to age, WHO grade, MGMT promoter methylation status, $I D H$-mutation status, and $1 \mathrm{p} / 19 \mathrm{q}$ codeletion status.

Multivariate analysis identified $I D H$ status and $\mathrm{rADC}_{\text {mean }}$ as the only prognostic factors that independently impacted overall survival after considering the WHO grade, MGMT promoter methylation, and $1 \mathrm{p} / 19 \mathrm{q}$ codeletion status and adjusting for $\mathrm{pa}-$ tient age. Specifically, IDH-mutant gliomas had significantly longer overall survival (median, 62.0 months) than $I D H$ wild-type gliomas (median, 14.7 months) $(P<.001$ by log-rank test; ageadjusted hazard ratio, 13.5 ; 95\% CI, $4.8-38.4 ; P<.001$ by multivariate Cox analysis). Overall cumulative survival rates were $97 \%$ at 1 year, $71 \%$ at 3 years, and $61 \%$ at 5 years in $I D H$-mutant gliomas, and $76 \%$ at 1 year and $13 \%$ at 3 years in $I D H$ wild-type gliomas. Gliomas with higher $\mathrm{rDCC}_{\text {mean }}$ had longer overall survival compared with those with lower $\operatorname{rADC}_{\text {mean }}(P=.001$ by univariate regression; age-adjusted hazard ratio, $0.17 ; 95 \% \mathrm{CI}$, $0.1-0.6 ; P=.004$ by multivariate Cox analysis). No statistically significant differences were noted for the remaining MR imaging features, WHO grade, MGMT promoter methylation status, and $1 \mathrm{p} / 19 \mathrm{q}$ codeletion status in multivariate analysis.

By means of the area under a time-dependent receiver operating characteristic curve for prediction of survival at 12 months, the optimal cutoff value of 1.08 for $\mathrm{rADC}_{\text {mean }}$ could differentiate survival differences within both $I D H$-mutant and $I D H$ wild-type gliomas. Patients having $I D H$-mutant gliomas with an $\mathrm{rADC}_{\text {mean }}$ below the cutoff value of 1.08 had poorer survival than those with an $\mathrm{rADC}_{\text {mean }}$ above $1.08(P<.001)$. In addition, median survival associated with $I D H$-mutant gliomas with a low $\mathrm{rADC}_{\text {mean }}$ was very poor. Survival time for this group was similar to that of those with $I D H$ wild-type gliomas with either high or low rADC $_{\text {mean }}$ (Table 2 and Fig 2). Finally, the $\mathrm{rADC}_{\text {mean }}$ cutoff value of 1.08 could also distinguish a survival difference within $I D H$ wild-type gliomas $(P<.041)$.

\section{DISCUSSION}

Mutations in the $I D H$ genes are among the most important diagnostic and prognostic markers of diffuse gliomas. ${ }^{20}$ Patients with $I D H$-mutant gliomas have significantly longer survival compared with those with $I D H$ wild-type gliomas, and management of these 2 molecular subgroups differs significantly. Previous studies have investigated the potential of various conventional and advanced MR imaging characteristics, including perfusion, diffusion tensor, and MR spectroscopy, in identifying genetic subtypes of diffuse gliomas. ${ }^{10,21,22}$ Here, our results indicate that rADC values correlate with $I D H$ mutation status as well as survival in both $I D H$-mutant and IDH wild-type diffuse gliomas, independent of their WHO grade. Additionally, using rADC, we could identify a particularly poor prognosis subset of $I D H$-mutant gliomas, with outcomes similar to those in patients IDH wild-type disease. Most important, determining the $\mathrm{rADC}$ value is a simple approach that requires no specialized software; hence, our findings potentially have immediate clinical impact.

The mechanism by which IDH-mutant and IDH wild-type gliomas differ in terms of the rADC is not clear; however, it may be related to tumor cellularity. In many previous studies, DWI has shown utility for preoperative grading and outcome of gliomas and for evaluating the response to therapy in patients with glioblastoma. ${ }^{13,23-27}$ ADC values provide quantitative information that reflects Brownian motion of water molecules within a scanned area and are determined by many factors. Mainly, differences in ADC have been attributed to tumor cellularity but also to the presence of necrosis or cysts and water content in interstitial space. ${ }^{11,13,28}$ ADC has been shown to correlate inversely with tumor cellularity on histologic examination, one of the main features of the WHO classification of brain tumors. Our results demonstrate that most $I D H$-mutant gliomas exhibit higher $\mathrm{rADC}_{\text {mean }}$ values and MR imaging features accordant with their low-grade features, while most $I D H$ wild-type gliomas show necrosis and a lower $\mathrm{rADC}_{\text {mean }}$ in solid portions, likely representing higher cellularity, which is associated with higher grade features.

Previous studies have observed an association between ADC and $I D H$ status in gliomas. One study of 37 anaplastic astrocytomas showed that the minimum ADC (cutoff point, $0.95 \times 10^{-3}$ $\mathrm{mm}^{2} / \mathrm{s}$ ) had acceptable discrimination (area under the curve, 


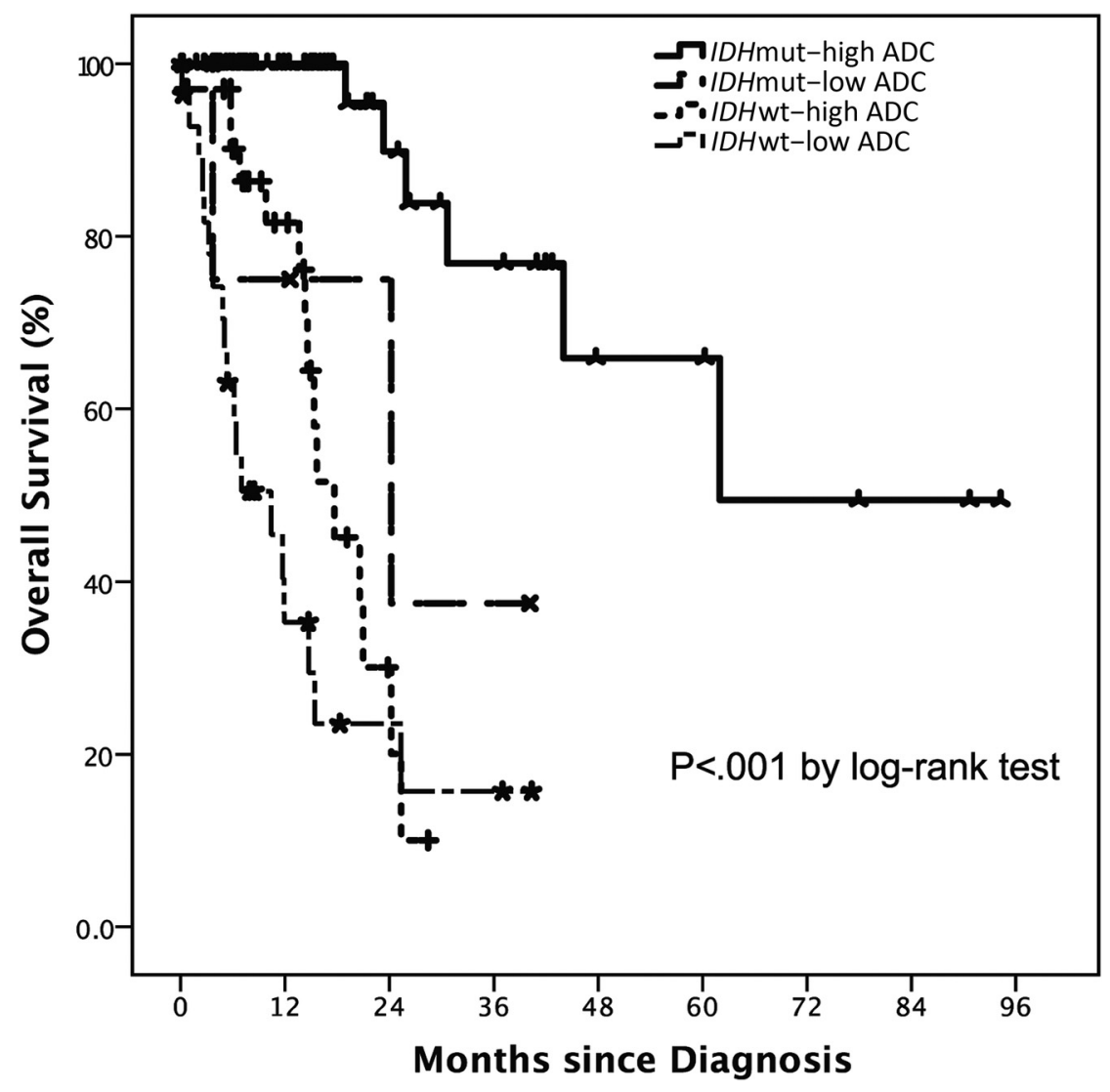

FIG 2. Kaplan-Meier survival curve subclassification for the present study by relative ADC and IDH genotype. Censored patients are annotated by a asterisks or plus signs. Results of the analysis are provided in Table 2. IDHmut indicates IDH-mutant; IDHwt, IDH wild-type.

$0.711 ; 95 \% \mathrm{CI}, 0.534-0.887)$ to predict the IDH status. ${ }^{29}$ Another retrospective study of 112 cases by Tan et $\mathrm{al}^{30}$ demonstrated that fractional anisotropy and ADC from diffusion tensor imaging can detect $I D H 1$ mutation in astrocytomas, with the ratio of $\mathrm{ADC}_{\min }$ being the best metric for detecting $I D H$ mutation, regardless of the WHO grade. We found that $\mathrm{rADC}_{\text {mean }}$ can differentiate $I D H$ wild-type from $I D H$-mutant gliomas with excellent discrimination, regardless of WHO grade. Our study also emphasizes MR imaging and $\mathrm{ADC}$ values correlating well with molecular subtype.

The main novel finding of our study is that preoperative rADC values can distinguish favorable and unfavorable prognosis within both $I D H$-mutant and $I D H$ wild-type glioma subgroups. While $I D H$-mutant gliomas generally behave less aggressively and have a better prognosis compared with their IDH wild-type counterparts, we identified a small subset $(12.5 \%)$ of $I D H$-mutant gliomas with low $\mathrm{rADC}_{\text {mean }}$ values and poor overall survival, which was only slightly better ( 24 months) than that of IDH wild-type gliomas but was not statistically significant. Concordantly, a study by Jiao et $\mathrm{al}^{31}$ revealed that a small subgroup (11.7\%) of patients with $I D H$-mutant gliomas across all grades had a dismal prognosis (median survival of 22 months), more similar to $I D H$ wild-type gliomas and glioblastomas in their cohort. These tumors had distinct genetic characteristics, lacking the typical concurrent genetic alterations observed in $I D H$-mutant gliomas. In addition, a recent study of The Cancer Genome Atlas identified a small subset (5.5\%) of $I D H$-mutant gliomas with markedly worse survival than other $I D H$-mutant gliomas, and these tumors were associ- ated with relatively decreased global DNA methylation. ${ }^{32}$ Together, these data clearly indicate that a subgroup of $I D H$-mutant gliomas behaves as aggressively as their $I D H$ wild-type counterparts. Although whether the malignant subgroups across these datasets represent the same biology is unknown, our results suggest that $\mathrm{rADC}$ values can potentially identify this aggressively behaving $I D H$-mutant subgroup.

Furthermore, our study highlights how detection of robust imaging-phenotype correlations can be significantly improved by analyzing glioma datasets by molecular subtype rather than by histopathologic classification. We evaluated MR imaging features and prognosis in diffuse gliomas across lower and higher grades in the current study and demonstrated the power of $\mathrm{rADC}_{\text {mean }}$ to differentiate $I D H$-mutation status and discrete survival subgroups beyond WHO grade. While many previous studies have demonstrated an inverse relationship between ADC and astrocytoma grade, ${ }^{12,13,28}$ other studies have shown substantial overlap of ADC values between high-versus-low-grade gliomas $3,24,33,34$ and no significant differences between grade II versus $\mathrm{III}^{35}$ or grade III versus IV. ${ }^{36,37}$ These observed variations of ADC in predicting tumor grade are likely due to limitations that make the exact histopathologic classification challenging, with high interobserver variability ${ }^{2}$ and molecular constituent and clinical behavior being likely different in tumors with the same histopathologic grade. ${ }^{3,4,38,39}$ Similar to a recent meta-analysis by Zulfiqar et $\mathrm{al}^{27}$ which showed that low ADC values correlate independently with poor survival in malignant astrocytomas (grades III and IV), 
we found an inverse relationship between $\mathrm{rADC}_{\text {mean }}$ values and prognosis for both $I D H$-mutant and $I D H$ wild-type tumors independent of WHO grade.

One limitation of our study is its retrospective design, which was necessary to include a relatively large number of patients and to correlate with survival, which is relatively long in patients with $I D H$ mutation. A second limitation is that the studied patients had been scanned on different MR imaging magnet types, and ADC maps were generated by diffusion-weighted imaging or diffusion tensor imaging of all collected data. However, a previous study has verified that ADC datasets from 3-directional DWI and 6-directional diffusion tensor imaging could be analyzed together. ${ }^{40}$ We calculated the rADC to minimize the differences among absolute ADC values across platforms. Third, the treatment regimen applied to each patient was not available to us in many cases. This issue might have potentially impacted the outcome and survival in each case. However, IDH status has been repeatedly shown to be an independent marker of prognosis in independent datasets. ${ }^{4}$ Finally, the ADC value has previously been reported to predict $1 \mathrm{p} / 19 \mathrm{q}$ codeletion status, a marker of oligodendroglioma, in lower grade gliomas. ${ }^{35,41}$ In the study by Johnson et $\mathrm{al}^{41}$ the ADC values were calculated from sampling both the highest and lowest ADC areas. However, we did not detect a significant correlation between $\mathrm{rADC}$ values and $1 \mathrm{p} / 19 \mathrm{q}$ codeletion status. Further investigation of the optimal methods of measuring ADC and physiology correlates of ADC values in genetically defined oligodendroglioma is needed.

Our results require independent confirmation, incorporating emerging molecular markers and accounting for different treatment strategies. However, our results expand on and refine the existing correlation between DWI and tumor genetic markers and highlight its potential role as an independent imaging biomarker that can aid in substratification of patients with gliomas, both $I D H$-mutant and IDH wild-type. Here, we were able to identify a subset of aggressive $\mathrm{IDH}$-mutant gliomas using ADC values easily obtained from common clinical MR images. Ongoing accumulation of tumorigenesis knowledge, together with imaging studies stratified by molecular subgroup rather than histopathologic features, will likely identify additional robust genetic-imaging-clinical phenotype correlations that will improve early detection of clinically meaningful glioma molecular subtypes.

\section{CONCLUSIONS}

We demonstrate that ADC values obtained from DWI correlate with $I D H$-mutation status and overall survival in adult diffuse gliomas. IDH wild-type gliomas showed low ADC values and poor survival compared with $I D H$-mutant gliomas. Within $I D H$ mutant gliomas, a small subgroup with lower ADC values had dismal survival, similar to that in $I D H$ wild-type gliomas. ADC values correlated with survival in patients with $I D H$-mutant and $I D H$ wild-type gliomas regardless of WHO grade. Preoperative ADC estimates may corroborate with molecular subtypes as a prognostic marker and potentially enhance risk stratification, especially within $I D H$-mutant gliomas.

Disclosures: Dimitris Placantonakis —UNRELATED: Grants/Grants Pending: National Institutes of Health, R01 NS102665, NY State Stem Cell Program - DOH01-STEM5-
2016-00221//C32595GG*; Patents (Planned, Pending or Issued): method for treating high-grade gliomas*. *Money paid to the Institution.

\section{REFERENCES}

1. Coons SW, Johnson PC, Scheithauer BW, et al. Improving diagnostic accuracy and interobserver concordance in the classification and grading of primary gliomas. Cancer 1997;79:1381-93 CrossRef Medline

2. van den Bent MJ. Interobserver variation of the histopathological diagnosis in clinical trials on glioma: a clinician's perspective. Acta Neuropathol 2010;120:297-304 CrossRef Medline

3. Cancer Genome Atlas Research Network; Brat DJ, Verhaak RG, Aldape KD, et al. Comprehensive, integrative genomic analysis of diffuse lower-grade gliomas. $N$ Engl J Med 2015;372:2481-98 CrossRef Medline

4. Louis DN, Perry A, Reifenberger G, et al. The 2016 World Health Organization Classification of Tumors of the Central Nervous System: a summary. Acta Neuropathol 2016;131:803-20 CrossRef Medline

5. Vigneswaran K, Neill S, Hadjipanayis CG. Beyond the World Health Organization grading of infiltrating gliomas: advances in the molecular genetics of glioma classification. Ann Transl Med 2015;3:95 CrossRef Medline

6. Turkalp Z, Karamchandani J, Das S. IDH mutation in glioma: new insights and promises for the future. JAMA Neurol 2014;71:1319-25 CrossRef Medline

7. Patel SH, Poisson LM, Brat DJ, et al. T2-FLAIR mismatch, an imaging biomarker for IDH and 1p/19q status in lower grade gliomas: a TCGA/TCIA project. Clin Cancer Res 2017;23:6078-85 CrossRef Medline

8. Wang YY, Wang K, Li SW, et al. Patterns of tumor contrast enhancement predict the prognosis of anaplastic gliomas with IDH1 mutation. AJNR Am J Neuroradiol 2015;36:2023-29 CrossRef Medline

9. Natsumeda M, Igarashi H, Nomura T, et al. Accumulation of 2-hydroxyglutarate in gliomas correlates with survival: a study by 3.0 Tesla magnetic resonance spectroscopy. Acta Neuropathol Commun 2014;2:158 CrossRef Medline

10. Kickingereder P, Sahm F, Radbruch A, et al. IDH mutation status is associated with a distinct hypoxia/angiogenesis transcriptome signature which is non-invasively predictable with $\mathrm{rCBV}$ imaging in human glioma. Sci Rep 2015;5:16238 CrossRef Medline

11. Gupta RK, Cloughesy TF, Sinha U, et al. Relationships between choline magnetic resonance spectroscopy, apparent diffusion coefficient and quantitative histopathology in human glioma. J Neurooncol 2000;50:215-26 CrossRef Medline

12. Yamasaki F, Kurisu K, Satoh K, et al. Apparent diffusion coefficient of human brain tumors at MR imaging. Radiology 2005;235:985-91 CrossRef Medline

13. Lee EJ, Lee SK, Agid R, et al. Preoperative grading of presumptive low-grade astrocytomas on MR imaging: diagnostic value of minimum apparent diffusion coefficient. AJNR Am J Neuroradiol 2008; 29:1872-77 CrossRef Medline

14. Hilario A, Ramos A, Perez-Nuñez A, et al. The added value of apparent diffusion coefficient to cerebral blood volume in the preoperative grading of diffuse gliomas. AJNR Am J Neuroradiol 2012;33: 701-07 CrossRef Medline

15. Zhang L, Min Z, Tang M, et al. The utility of diffusion MRI with quantitative ADC measurements for differentiating high-grade from low-grade cerebral gliomas: evidence from a meta-analysis. J Neurol Sci 2017;373:9-15 CrossRef Medline

16. TCGA-GBM collection from The Cancer Imaging Archive (TCIA). https://wiki.cancerimagingarchive.net/display/Public/TCGA-GBM. Accessed April 01, 2016

17. TCGA-LGG collection from The Cancer Imaging Archive (TCIA). https://wiki.cancerimagingarchive.net/display/Public/TCGA-LGG. Accessed April 01, 2016

18. Clark K, Vendt B, Smith K, et al. The Cancer Imaging Archive (TCIA): maintaining and operating a public information repository. J Digit Imaging 2013;26:1045-57 CrossRef Medline 
19. Wiki for the VASARI feature set The National Cancer Institute Web site. https://wikicancerimagingarchivenet/display/Public/VASARI+ Research + Project. Updated July 25, 2016

20. Eckel-Passow JE, Lachance DH, Molinaro AM, et al. Glioma groups based on $1 \mathrm{p} / 19 \mathrm{q}, \mathrm{IDH}$, and TERT promoter mutations in tumors. N Engl J Med 2015;372:2499-508 CrossRef Medline

21. Xiong J, Tan W, Wen J, et al. Combination of diffusion tensor imaging and conventional MRI correlates with isocitrate dehydrogenase $1 / 2$ mutations but not $1 \mathrm{p} / 19 \mathrm{q}$ genotyping in oligodendroglial tumours. Eur Radiol 2016;26:1705-15 CrossRef Medline

22. Leu K, Ott GA, Lai A, et al. Perfusion and diffusion MRI signatures in histologic and genetic subtypes of WHO grade II-III diffuse gliomas. J Neurooncol 2017;134:177-88 CrossRef Medline

23. Murakami R, Hirai T, Kitajima M, et al. Magnetic resonance imaging of pilocytic astrocytomas: usefulness of the minimum apparent diffusion coefficient (ADC) value for differentiation from high-grade gliomas. Acta Radiol 2008;49:462-67 CrossRef Medline

24. Higano S, Yun X, Kumabe T, et al. Malignant astrocytic tumors: clinical importance of apparent diffusion coefficient in prediction of grade and prognosis. Radiology 2006;241:839-46 CrossRef Medline

25. Murakami R, Sugahara T, Nakamura H, et al. Malignant supratentorial astrocytoma treated with postoperative radiation therapy: prognostic value of pretreatment quantitative diffusion-weighted MR imaging. Radiology 2007;243:493-99 CrossRef Medline

26. Yamasaki F, Sugiyama K, Ohtaki M, et al. Glioblastoma treated with postoperative radio-chemotherapy: prognostic value of apparent diffusion coefficient at MR imaging. Eur J Radiol 2010;73:532-37 CrossRef Medline

27. Zulfiqar M, Yousem DM, Lai H. ADC values and prognosis of malignant astrocytomas: does lower ADC predict a worse prognosis independent of grade of tumor? A meta-analysis. AJR Am J Roentgenology 2013;200:624-29 CrossRef Medline

28. Sugahara T, Korogi Y, Kochi M, et al. Usefulness of diffusion-weighted MRI with echo-planar technique in the evaluation of cellularity in gliomas. J Magn Reson Imaging 1999;9:53-60 CrossRef Medline

29. Wasserman JK, Nicholas G, Yaworski R, et al. Radiological and pathological features associated with IDH1-R132H mutation status and early mortality in newly diagnosed anaplastic astrocytic tumours. PLoS One 2015;10:e0123890 CrossRef Medline

30. Tan WL, Huang WY, Yin B, et al. Can diffusion tensor imaging noninvasively detect IDH1 gene mutations in astrogliomas? A ret- rospective study of 112 cases. AJNR Am J Neuroradiol 2014;35: 920-27 CrossRef Medline

31. Jiao Y, Killela PJ, Reitman ZJ, et al. Frequent ATRX, CIC, FUBP1 and IDH1 mutations refine the classification of malignant gliomas. $\mathrm{On}$ cotarget 2012;3:709-22 CrossRef Medline

32. Ceccarelli M, Barthel FP, Malta TM, et al. Molecular profiling reveals biologically discrete subsets and pathways of progression in diffuse glioma. Cell 2016;164:550-63 CrossRef Medline

33. Lam WW, Poon WS, Metreweli C. Diffusion MR imaging in glioma: does it have any role in the pre-operation determination of grading of glioma? Clin Radiol 2002;57:219-25 CrossRef Medline

34. Murakami R, Hirai T, Sugahara T, et al. Grading astrocytic tumors by using apparent diffusion coefficient parameters: superiority of a one- versus two-parameter pilot method. Radiology 2009;251: 838-45 CrossRef Medline

35. Khayal IS, Vandenberg SR, Smith KJ, et al. MRI apparent diffusion coefficient reflects histopathologic subtype, axonal disruption, and tumor fraction in diffuse-type grade II gliomas. Neuro Oncol 2011; 13:1192-201 CrossRef Medline

36. Kang Y, Choi SH, Kim YJ, et al. Gliomas: histogram analysis of apparent diffusion coefficient maps with standard- or high-b-value diffusion-weighted MR imaging-correlation with tumor grade. Radiology 2011;261:882-90 CrossRef Medline

37. Kitis $\mathrm{O}$, Altay $\mathrm{H}$, Calli $\mathrm{C}$, et al. Minimum apparent diffusion coefficients in the evaluation of brain tumors. Eur J Radiol 2005;55:393400 Medline

38. Olar A, Wani KM, Alfaro-Munoz KD, et al. IDH mutation status and role of WHO grade and mitotic index in overall survival in grade II-III diffuse gliomas. Acta Neuropathol 2015;129:585-96 CrossRef Medline

39. Reuss DE, Mamatjan Y, Schrimpf D, et al. IDH mutant diffuse and anaplastic astrocytomas have similar age at presentation and little difference in survival: a grading problem for WHO. Acta Neuropathol 2015;129:867-73 CrossRef Medline

40. Khayal IS, McKnight TR, McGue C, et al. Apparent diffusion coefficient and fractional anisotropy of newly diagnosed grade II gliomas. NMR Biomed 2009;22:449-55 CrossRef Medline

41. Johnson DR, Diehn FE, Giannini C, et al. Genetically defined oligodendroglioma is characterized by indistinct tumor borders at MRI. AJNR Am J Neuroradiol 2017;38:678-84 CrossRef Medline 